\title{
What Factors are Associated with Where Women Undergo Clinical Breast Examination? Results from the 2005 National Health Interview Survey
}

\author{
Steven S. Coughlin*, Susan A. Sabatino and Kate M. Shaw
}

\author{
Division of Cancer Prevention and Control, National Center for Chronic Disease Prevention and Health Promotion, \\ Centers for Disease Control and Atlanta, GA, USA
}

\begin{abstract}
Background: Recent studies have suggested that clinical breast examination (CBE) rates may vary according to patient, provider and health care system characteristics.

Objective: To examine the locations where U.S. women received a CBE and other general preventive health, and to examine predictors of location of receipt of general preventive health care (including a recent CBE).

Design: Age-specific and age-adjusted rates of CBE use were calculated using Statistical Analysis Software (SAS) and SUDAAN. A multivariate analysis was carried out using logistic regression techniques.

Participants: Women aged 40 years and older $(n=10,002)$ who participated in the 2005 National Health Interview Survey (NHIS).

Measurements: Recent CBE use was defined as within the past two years.

Results: Among all women, $65 \%$ reported a CBE within two years. The highest rate was found among women receiving routine care from doctors' offices and health maintenance organizations (HMOs) (68.5\%). CBE use was somewhat lower among women receiving routine care from clinics or health centers $(62.9 \%)$, and substantially lower among women receiving care from "other" locations $(28.4 \%)$ or not reporting receiving preventive care $(25.3 \%)$. Low income women (p < $.01)$ and those with less than a high school education $(\mathrm{p}<.01)$ are more likely to go to a hospital than higher SES women. Women with health insurance are much more likely than women without health insurance to go to a doctor's office or HMO, and less likely to be seen at a clinic or health center ( $p<.01$ in both instances). In multivariate analysis, women who received routine care in a location other than a clinic or health center, doctor's office or HMO, or hospital outpatient department (OPD) were less likely to have received a $\mathrm{CBE}$ within the past two years (adjusted $\mathrm{OR}=0.4,95 \% \mathrm{CI}=0.3$, 0.7) compared to those at a doctor's office or HMO.
\end{abstract}

Conclusions: After adjusting for patient factors, clinics/health centers and hospital OPDs performed as well as doctors' offices/HMOs in delivering CBE. However, women receiving care in other locations were less likely to report CBE.

Keywords: Breast cancer, clinical breast examination, physicians, primary health care.

\section{INTRODUCTION}

Over the past decade, major efforts have been made to increase adherence with guidelines for routine breast cancer screening among United States women. The U.S. Preventive Services Task Force recommends screening mammography every 1 to 2 years, with or without clinical breast examination (CBE), among women aged 40 and older [1]. The Task Force concluded that there is insufficient evidence to recommend for or against routine $\mathrm{CBE}$ alone to screen for breast cancer. CBE may detect some breast cancers missed by mammography [2], and some suggest a role for CBE as part of comprehensive breast cancer screening $[3,4]$.

Factors associated with not having received a CBE include lack of health insurance, low income, older age, lower education, non-white race, and Hispanic ethnicity [4]. Sur-

*Address correspondence to this author at the Epidemiology and Applied Research Branch, Division of Cancer Prevention and Control, Atlanta, GA 30341, USA; Tel: (770) 488-4776; Fax: (770) 488-4639;

E-mail: sic9@cdc.gov veys of healthcare providers have identified several barriers to performing $\mathrm{CBE}$, including clinician discomfort, lack of confidence in performing the examination, lack of time, reliance on mammography as the preferred method of screening, and patient embarrassment or refusal [4]. Gender and specialty also may influence whether a physician performs a CBE [4]. Efforts to ensure that all women have access to routine screening for breast cancer include screening in nontraditional settings [5]. Clarifying where women receive a CBE is important because many interventions for maintaining or increasing cancer screening rates (for example, clinic and physician reminder systems) are specific to particular health care settings (http://www.thecommunityguide.org).

Meissner et al. [4] examined trends in CBE for white, black, and Hispanic women from 1990 to 2000 using NHIS data. Although most women reported receiving a recent CBE in both years, the proportion of U.S. women reporting a recent CBE decreased for almost all groups of women, especially those without health insurance, recent immigrants, and women of Hispanic ethnicity [4]. This decline may reflect changing breast cancer screening practices and sole reliance 
on mammography for early detection of breast cancer, or access to clinical services [4]. The authors concluded that healthcare providers should be aware of the lower rates of CBE, particularly among women with decreased access to health care, and that providers should not assume that women who get mammograms have received comprehensive screening for breast cancer [4]. More information is needed to understand how $\mathrm{CBE}$ is being used as part of breast cancer screening.

The objectives of this study were to examine how CBE use varies according to location of receipt of general preventive health care [clinic or health center, private doctor's office or HMO, hospital outpatient department (OPD), emergency room (ER) or "other" location, or none], and to identify factors associated with CBE use in those different clinical settings. For example, are low income women or women from major racial and ethnic subgroups (e.g., black women or Hispanic women) more likely to receive a CBE at certain locations? Are women without health insurance or women with certain types of insurance more likely to receive a $\mathrm{CBE}$ at certain locations?

\section{METHODS}

We used data from the 2005 National Health Interview Survey (NHIS) including the sample adult module and cancer control topical module. NHIS is administered by the Census Bureau under contract to the National Center for Health Statistics (NCHS). The survey incorporates a multistage probability sampling design and includes health information about a nationally representative sample of the civilian, non-institutionalized U.S. population. For 2005, the overall household response rate was $86.5 \%$, with an overall response rate for the sample adult module of $69.0 \%$.The interviews included questions about general health status, demographic and socioeconomic characteristics, CBE, mammography, and various other factors. Each adult female respondent was asked whether she had ever had a CBE and, if so, how long it had been since her last CBE. Recent CBE use was defined as within the past two years. Respondents were asked similar questions regarding mammography. In addition, they were asked whether there is a place that they usually go to when they are sick or need advice about their health (clinic or health center, doctor's office or HMO, hospital OPD, ER or other location, or doesn't get preventive care anywhere).

The study population for this analysis consisted of women aged 40 years and older $(n=11,037)$. Characteristics of women who reported that they had a CBE in the past 2 years were examined in relation to where they generally receive routine health care services. Women with missing data for a $\mathrm{CBE}$ or place of routine health care services were excluded from the analyses for a sample size of 10,002. Agespecific and crude rates of CBE use were calculated using SAS and SUDAAN to calculate the $95 \%$ confidence intervals (CIs) and to allow for weighting of the estimates in order to take into account the complex sampling design. Linear contrasts were used to test for statistical significance [6]. A multivariate analysis of predictors of CBE use including locations where women receive health care, was carried out using logistic regression techniques and SUDAAN. Predicted marginals, or adjusted CBE rates expressed as percentages, were obtained from point estimates [7]. Covariates for age categories were included in the model in order to adjust for age differences. Variables were included for health insurance coverage, race, Hispanic ethnicity, and usual location for receipt of routine health care services, along with potential confounders (household income, marital status, education, employment status, family size, health status, gynecology visit in past year, mammogram in past 2 years, region of the U.S., and length of residence in the U.S.). To avoid over parameterization of the model, a covariate for having a usual source of care was not included.

\section{RESULTS}

The percentage distribution of women in this sample according to a variety of characteristics, and by usual location for receipt of routine health care is shown in Appendix A. A majority of the women (79.4\%) went to a doctor's office or HMO for routine health care, followed by a clinic or health center $(13.6 \%)$. About $1.0 \%$ each went to a hospital OPD or ER/other place for routine health care. At least $4.5 \%$ of the women reported not receiving preventive health care anywhere. Receiving routine care from clinics was less likely among women over age 64 years and more commonly reported among women who were American Indian or Alaska Native (AI/AN), Hispanic, black, single, divorced or separated, less educated, uninsured, lower income and in fair or poor health status compared with women in their respective reference groups. AI/AN women were particularly more likely than other women to report receiving care at clinics or health centers. Women from the Midwest or West, or with no recent mammogram or gynecology visit were also more likely than their reference groups to report care from a clinic. Characteristics of women more likely to report receiving routine care from hospital OPDs or from ERs were generally similar to those of women receiving care in other locations. Women were more likely to report care from these settings if they were black, Hispanic, single (hospital OPDs), less educated, lower income, unemployed, or from the West.

Women in fair or poor health status were more likely to report care from a hospital than women in good health. Women with a recent gynecology visit were more likely to report care from a hospital OPD than without such a visit, although the opposite was true for ERs and other places of routine care. Uninsured women and women with no recent mammogram were more likely to report care from an ER or other location.

Hispanic women are more likely than non-Hispanic women to go to a clinic or health center, hospital OPD, ER or other location, and less likely to be seen at a doctor's office or HMO ( $\mathrm{p}<.01$ in each instance). Although differences were small, Black women are more likely than white women to go to a hospital OPD $(\mathrm{p}<.01)$. Low income women $(\mathrm{p}<$ $.01)$ and those with less than a high school education ( $\mathrm{p}<$ .01) are more likely to go to a hospital than higher SES women. Women with health insurance are much more likely than women without health insurance to go to a doctor's office or HMO, and less likely to be seen at a clinic or health center ( $\mathrm{p}<.01$ in both instances).

Table 1a and 1b show rates of CBE use and bivariable associations with $\mathrm{CBE}$ for the sample overall, and across different settings. Among all women, 65\% reported a CBE within two years. The highest rate was found among women 
Table 1a. Percentage of women in the United States, aged 40 years or older, who had received a clinical breast examination in the past 2 years, by age, race, Hispanic ethnicity, and other characteristics, and according to their usual place for routine health care, National Health Interview Survey, $2005^{1}$

\begin{tabular}{|c|c|c|c|c|c|c|c|c|c|}
\hline \multirow[b]{2}{*}{ Characteristic } & \multicolumn{3}{|c|}{ Total $(n=10022)$} & \multicolumn{3}{|c|}{ Clinic or Health Center $(n=1469)$} & \multicolumn{3}{|c|}{ Doctor's Office or HMO $(n=7746)$} \\
\hline & $\%$ & $(95 \% \mathrm{CI})$ & p-value & $\%$ & $(95 \% \mathrm{CI})$ & p-value & $\%$ & $(95 \% \mathrm{CI})$ & p-value \\
\hline Total & 65.0 & $(63.8-66.1)$ & -- & 62.9 & $(59.6-66.1)$ & -- & 68.5 & $(67.3-69.7)$ & -- \\
\hline \multicolumn{10}{|l|}{ Age (years) } \\
\hline $40-49$ & 68.9 & $(67.1-70.7)$ & 0.34 & 65.7 & $(61.0-70.2)$ & 0.43 & 73.7 & $(71.5-75.8)$ & 0.36 \\
\hline $50-64$ & 67.7 & $(66.0-69.4)$ & ref & 63.1 & $(58.0-68.0)$ & ref & 72.4 & $(70.5-74.2)$ & ref \\
\hline$\geq 75$ & 51.3 & $(48.4-54.1)$ & $<0.01$ & 60.9 & $(52.1-69.0)$ & 0.64 & 50.8 & $(47.7-53.9)$ & $<0.01$ \\
\hline \multicolumn{10}{|l|}{ Race } \\
\hline White & 66.1 & $(64.9-67.4)$ & ref & 64.7 & $(60.8-68.3)$ & ref & 69.5 & $(68.1-70.8)$ & ref \\
\hline Black & 61.9 & $(58.3-65.4)$ & 0.03 & 60.5 & $(52.5-68.0)$ & 0.36 & 65.5 & $(61.6-69.2)$ & 0.06 \\
\hline \multicolumn{10}{|l|}{ Hispanic } \\
\hline Yes & 49.9 & $(46.1-53.7)$ & $<0.01$ & 46.2 & $(38.4-54.2)$ & $<0.01$ & 56.0 & $(51.3-60.5)$ & $<0.01$ \\
\hline No & 66.5 & $(65.2-67.7)$ & ref & 65.6 & $(62.0-69.0)$ & ref & 69.4 & $(68.1-70.6)$ & ref \\
\hline \multicolumn{10}{|l|}{ Marital Status } \\
\hline Currently married & 68.8 & $(67.2-70.3)$ & ref & 68.8 & $(64.3-73.0)$ & ref & 71.2 & $(69.5-72.9)$ & ref \\
\hline Divorced or separated & 63.1 & $(60.4-65.6)$ & $<0.01$ & 64.5 & $(58.0-70.5)$ & 0.28 & 67.5 & $(64.6-70.3)$ & 0.02 \\
\hline Widowed & 57.8 & $(52.5-63.1)$ & $<0.01$ & 52.3 & $(41.4-63.0)$ & $<0.01$ & 61.8 & $(55.3-67.8)$ & $<0.01$ \\
\hline Never married & 57.7 & $(53.4-61.8)$ & $<0.01$ & 53.9 & $(44.6-62.8)$ & $<0.01$ & 62.6 & $(57.3-67.6)$ & $<0.01$ \\
\hline College graduate & 73.2 & $(70.7-75.5)$ & $<0.01$ & 71.3 & $(63.7-77.8)$ & $<0.01$ & 74.9 & $(72.3-77.4)$ & $<0.01$ \\
\hline \multicolumn{10}{|l|}{ Family Income } \\
\hline$\leq \$ 14,999$ & 50.0 & $(47.0-53.0)$ & $<0.01$ & 47.8 & $(41.7-53.9)$ & $<0.01$ & 59.2 & $(55.2-63.1)$ & $<0.01$ \\
\hline$\$ 15,000-\$ 34,999$ & 58.2 & $(55.9-60.5)$ & $<0.01$ & 59.5 & $(53.8-64.9)$ & $<0.01$ & 62.5 & $(59.7-65.2)$ & $<0.01$ \\
\hline$\$ 35,000-\$ 54,999$ & 65.9 & $(63.1-68.5)$ & $<0.01$ & 67.3 & $(58.7-74.8)$ & 0.24 & 68.1 & $(65.0-71.1)$ & 0.04 \\
\hline$\geq \$ 55,000$ & 71.6 & $(69.0-74.0)$ & ref & 73.8 & $(66.6-79.9)$ & ref & 72.8 & $(70.0-75.4)$ & ref \\
\hline \multicolumn{10}{|l|}{ Employment } \\
\hline Employed & 70.0 & $(67.6-72.3)$ & ref & 68.0 & $(61.4-74.0)$ & ref & 72.7 & $(70.2-75.1)$ & ref \\
\hline Homemaker/Retired & 60.9 & $(58.3-63.3)$ & $<0.01$ & 60.7 & $(53.9-67.1)$ & 0.12 & 65.7 & $(62.7-68.6)$ & $<0.01$ \\
\hline Unemployed & 57.6 & $(54.2-61.0)$ & $<0.01$ & 54.0 & $(45.4-62.4)$ & 0.01 & 61.8 & $(58.1-65.4)$ & $<0.01$ \\
\hline \multicolumn{10}{|l|}{ Family Size } \\
\hline 1 & 62.6 & $(60.6-64.5)$ & ref & 62.7 & $(57.2-67.8)$ & ref & 66.9 & $(64.7-69.0)$ & ref \\
\hline 2 & 68.0 & $(66.3-69.7)$ & $<0.01$ & 65.7 & $(60.4-70.6)$ & 0.41 & 71.2 & $(69.3-73.0)$ & $<0.01$ \\
\hline
\end{tabular}


(Table 1a). Contd.....

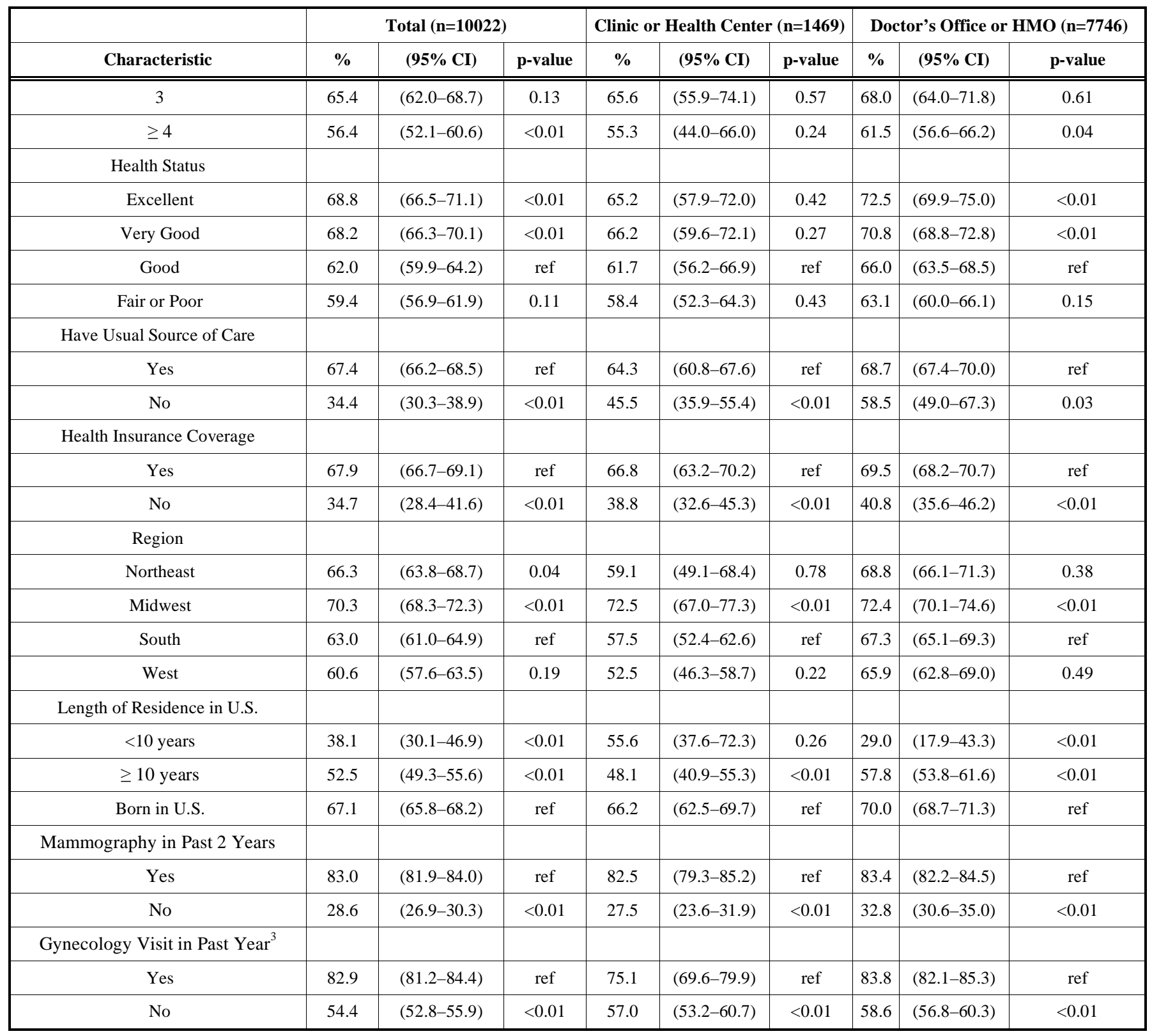

${ }^{1}$ Except for age, results are adjusted for age using survey population. Estimates are weighted; p-values are for tests comparing characteristic levels to referent level. Not ascertained, refused, or don't know responses were excluded.

${ }^{2}$ Asian includes Asian Indian, Chinese, Filipino, and Other Asian.

${ }^{3}$ Respondents were asked if they had seen or talked to a doctor who specializes in women's health in the past 12 months.

$* *$ Not reportable, sample size $<30$ and/or relative standard error $>50 \%$.

Table 1b. Percentage of women in the United States, aged 40 years or older, who had received a clinical breast examination in the past 2 years, by age, race, Hispanic ethnicity, and other characteristics, and according to their usual place for routine health care, National Health Interview Survey, $\mathbf{2 0 0 5}^{1}$

\begin{tabular}{|c|c|c|c|c|c|c|c|c|c|}
\hline \multirow[b]{2}{*}{ Characteristic } & \multicolumn{3}{|c|}{$\begin{array}{c}\text { Hospital Outpatient Department } \\
\qquad(\mathrm{n}=125)\end{array}$} & \multicolumn{3}{|c|}{ Other $^{2}(n=163)$} & \multicolumn{3}{|c|}{$\begin{array}{l}\text { Doesn't get preventive care anywhere } \\
\qquad(\mathrm{n}=519)\end{array}$} \\
\hline & $\%$ & $(95 \% \mathrm{CI})$ & p-value & $\%$ & $(95 \% \mathrm{CI})$ & p-value & $\%$ & $(95 \% \mathrm{CI})$ & p-value \\
\hline \multicolumn{10}{|l|}{ Age (years) } \\
\hline $40-49$ & 57.7 & $(38.6-74.7)$ & 0.40 & 42.2 & $(29.6-55.9)$ & 0.01 & 29.3 & $(22.7-36.8)$ & 0.49 \\
\hline$\geq 75$ & $* *$ & & & $* *$ & & & $18.5^{\S}$ & $(7.4-39.1)$ & 0.42 \\
\hline
\end{tabular}


(Table 1b). Contd.....

\begin{tabular}{|c|c|c|c|c|c|c|c|c|c|}
\hline \multirow[b]{2}{*}{ Characteristic } & \multicolumn{3}{|c|}{$\begin{array}{l}\text { Hospital Outpatient Department } \\
\qquad(n=125)\end{array}$} & \multicolumn{3}{|c|}{$\operatorname{Other}^{2}(n=163)$} & \multicolumn{3}{|c|}{$\begin{array}{l}\text { Doesn't get preventive care anywhere } \\
\qquad(n=519)\end{array}$} \\
\hline & $\%$ & $(95 \% \mathrm{CI})$ & p-value & $\%$ & $(95 \% \mathrm{CI})$ & p-value & $\%$ & $(95 \% \mathrm{CI})$ & p-value \\
\hline \multicolumn{10}{|l|}{ Race } \\
\hline White & 62.1 & $(49.9-73.0)$ & ref & 30.5 & $(21.4-41.6)$ & ref & 25.9 & $(21.1-31.5)$ & ref \\
\hline Black & 71.5 & $(53.8-84.3)$ & 0.34 & $20.6^{\S}$ & $(10.7-36.0)$ & 0.19 & 20.0 & $(12.3-30.9)$ & 0.26 \\
\hline$A \operatorname{sian}^{3}$ & $* *$ & & & $* *$ & & & $* *$ & & \\
\hline $\begin{array}{l}\text { American Indian/ } \\
\text { Alaskan Native }\end{array}$ & $* *$ & & & $* *$ & & & $* *$ & & \\
\hline \multicolumn{10}{|l|}{ Hispanic } \\
\hline Yes & 60.0 & $(45.7-72.8)$ & 0.77 & $22.8^{\S}$ & $(10.7-42.3)$ & 0.53 & 31.2 & $(19.6-45.8)$ & 0.33 \\
\hline No & 62.7 & $(50.4-73.5)$ & ref & 28.8 & $(19.7-40.0)$ & ref & 24.1 & $(19.4-29.7)$ & ref \\
\hline \multicolumn{10}{|l|}{ Marital Status } \\
\hline Currently married & 72.7 & $(56.7-84.4)$ & ref & 40.1 & $(30.1-51.0)$ & ref & 29.0 & $(21.4-38.0)$ & ref \\
\hline Divorced or separated & 50.5 & $(32.0-68.8)$ & 0.07 & 31.5 & $(17.6-49.9)$ & 0.41 & 24.3 & $(17.5-32.8)$ & 0.43 \\
\hline Widowed & $* *$ & & & $* *$ & & & $26.7^{\S}$ & $(13.6-45.8)$ & 0.80 \\
\hline Never married & $* *$ & & & $* *$ & & & 21.2 & $(11.5-35.8)$ & 0.30 \\
\hline Living with partner & $* *$ & & & $* *$ & & & $* *$ & & \\
\hline \multicolumn{10}{|l|}{ Education } \\
\hline$<$ High school graduate & 56.7 & $(40.4-71.7)$ & 0.57 & $8.4^{\S}$ & $(3.1-20.6)$ & 0.01 & 16.8 & $(10.1-26.6)$ & 0.06 \\
\hline $\begin{array}{l}\text { High school graduate/ } \\
\text { GED }\end{array}$ & 62.8 & $(48.1-75.5)$ & ref & 29.5 & $(17.3-45.6)$ & ref & 28.1 & $(20.9-36.7)$ & ref \\
\hline $\begin{array}{l}\text { Some college/ } \\
\text { Tech school }\end{array}$ & $* *$ & & & 46.7 & $(34.0-59.7)$ & 0.08 & 34.6 & $(23.4-47.9)$ & 0.40 \\
\hline College graduate & $* *$ & & & 39.8 & $(24.2-57.9)$ & 0.38 & 35.0 & $(22.5-49.8)$ & 0.40 \\
\hline \multicolumn{10}{|l|}{ Family Income } \\
\hline$\leq \$ 14,999$ & 53.4 & $(32.8-73.0)$ & & $20.1^{\S}$ & $(10.3-35.7)$ & 0.04 & 19.4 & $(13.4-27.2)$ & 0.15 \\
\hline$\$ 15,000-\$ 34,999$ & 72.4 & $(53.5-85.6)$ & & $19.2^{\S}$ & $(6.5-45.1)$ & 0.08 & 24.0 & $(17.1-32.7)$ & 0.38 \\
\hline$\$ 35,000$ - $\$ 54,999$ & $* *$ & & & $* *$ & & & 31.8 & $(20.3-46.1)$ & 0.98 \\
\hline$\geq \$ 55,000$ & $* *$ & & & 43.0 & $(25.8-61.9)$ & ref & 32.1 & $(18.4-49.8)$ & ref \\
\hline \multicolumn{10}{|l|}{ Employment } \\
\hline Employed & 71.6 & $(57.3-82.6)$ & ref & 37.9 & $(24.1-54.1)$ & ref & 25.8 & $(19.2-33.7)$ & ref \\
\hline Homemaker/Retired & 56.9 & $(37.6-74.2)$ & 0.20 & $15.0^{\S}$ & $(6.7-30.6)$ & 0.02 & 20.2 & $(13.8-28.6)$ & 0.31 \\
\hline Unemployed & 57.5 & $(40.9-72.6)$ & 0.17 & 37.2 & $(23.2-53.6)$ & 0.94 & 30.7 & $(20.2-43.7)$ & 0.47 \\
\hline \multicolumn{10}{|l|}{ Family Size } \\
\hline 1 & 60.4 & $(46.7-72.7)$ & ref & 21.0 & $(12.0-34.2)$ & ref & 26.2 & $(19.6-34.0)$ & ref \\
\hline 2 & 70.7 & $(53.3-83.6)$ & 0.33 & 34.4 & $(20.6-51.4)$ & 0.13 & 27.3 & $(20.0-36.1)$ & 0.83 \\
\hline 3 & $* *$ & & & $* *$ & & & 25.7 & $(17.0-36.9)$ & 0.95 \\
\hline$\geq 4$ & $* *$ & & & 14.5 & $(8.0-24.8)$ & 0.35 & 22.2 & $(13.1-35.0)$ & 0.55 \\
\hline \multicolumn{10}{|l|}{ Health Status } \\
\hline Excellent & $* *$ & & & $17.7^{\S}$ & $(8.9-32.3)$ & 0.04 & 27.1 & $(17.8-39.1)$ & 0.44 \\
\hline Very Good & $* *$ & & & $28.0^{\S}$ & $(14.7-46.8)$ & 0.43 & 27.5 & $(20.0-36.7)$ & 0.33 \\
\hline Good & 70.6 & $(53.2-83.6)$ & ref & 36.8 & $(24.2-51.6)$ & ref & 21.4 & $(13.8-31.8)$ & ref \\
\hline Fair or Poor & 49.5 & $(33.8-65.2)$ & 0.06 & 39.0 & $(23.4-57.3)$ & 0.85 & 29.6 & $(20.4-40.7)$ & 0.26 \\
\hline
\end{tabular}


(Table 1b). Contd.....

\begin{tabular}{|c|c|c|c|c|c|c|c|c|c|}
\hline \multirow[b]{2}{*}{ Characteristic } & \multicolumn{3}{|c|}{$\begin{array}{l}\text { Hospital Outpatient Department } \\
\qquad(\mathrm{n}=125)\end{array}$} & \multicolumn{3}{|c|}{$\operatorname{Other}^{2}(n=163)$} & \multicolumn{3}{|c|}{$\begin{array}{l}\text { Doesn't get preventive care anywhere } \\
\qquad(\mathrm{n}=519)\end{array}$} \\
\hline & $\%$ & $(95 \%$ CI $)$ & p-value & $\%$ & $(95 \%$ CI $)$ & p-value & $\%$ & $(95 \% \mathrm{CI})$ & p-value \\
\hline Yes & 63.0 & $(52.1-72.7)$ & & 41.3 & $(27.7-56.3)$ & ref & 28.3 & (19.9-38.5) & ref \\
\hline \multicolumn{10}{|c|}{$\begin{array}{l}\text { Health Insurance Cover- } \\
\text { age }\end{array}$} \\
\hline Yes & 65.6 & $(53.8-75.8)$ & & 41.5 & (29.6-54.6) & ref & 25.3 & $(18.9-32.8)$ & ref \\
\hline No & $* *$ & & & 17.0 & $(10.3-26.7)$ & $<0.01$ & 38.0 & $(30.2-46.5)$ & 0.02 \\
\hline \multicolumn{10}{|l|}{ Region } \\
\hline West & 40.5 & $(26.1-56.8)$ & 0.05 & 22.3 & $(14.0-33.5)$ & 0.49 & 39.6 & $(29.3-50.9)$ & 0.02 \\
\hline \multicolumn{10}{|c|}{$\begin{array}{c}\text { Length of Residence in } \\
\text { U.S. }\end{array}$} \\
\hline$<10$ years & $* *$ & & & $* *$ & & & 45.5 & (26.7-65.6) & 0.03 \\
\hline$\geq 10$ years & 45.5 & $(32.5-59.2)$ & 0.02 & $15.8^{\S}$ & $(6.6-33.3)$ & 0.04 & 30.2 & $(18.6-45.1)$ & 0.29 \\
\hline Born in U.S. & 67.2 & $(54.6-77.6)$ & ref & 34.4 & $(23.5-47.2)$ & ref & 22.4 & $(17.8-27.8)$ & ref \\
\hline \multicolumn{10}{|c|}{$\begin{array}{l}\text { Mammography in Past } 2 \\
\text { Years }\end{array}$} \\
\hline Yes & 78.5 & $(65.7-87.4)$ & ref & 72.4 & $(58.1-83.2)$ & ref & 75.0 & $(65.6-82.5)$ & ref \\
\hline
\end{tabular}

${ }^{1}$ Except for age, results are adjusted for age using survey population. Estimates are weighted; p-values are for tests comparing characteristic levels to referent level. Not ascertained, refused, or don't know responses were excluded.

${ }^{2}$ Hospital emergency room, some other place, or doesn't go to one place for routine care most often.

${ }^{3}$ Asian includes Asian Indian, Chinese, Filipino, and Other Asian.

${ }^{4}$ Respondents were asked if they had seen or talked to a doctor who specializes in women's health in the past 12 months.

$\S$ Relative standard error $30-50 \%$, interpret results with caution.

$* *$ Not reportable, sample size $<30$ and/or relative standard error $>50 \%$.

receiving routine care from doctors' offices and HMOs $(68.5 \%)$ as shown in Table 1a. CBE use was substantially lower among women receiving care from ERs or "other" locations $(28.4 \%)$ or not reporting receiving preventive care $(25.3 \%)$. Women older than 64 years were generally less likely than women aged 50-64 to report a recent CBE, although this difference was significant only among women cared for at doctors' offices or HMOs. In both clinics and doctors' offices/HMOs, Asian and Hispanic women were less likely than white and non-Hispanic women to report recent CBEs, and married women were most likely to report an exam. Higher education was also associated with $\mathrm{CBE}$ use across settings, as were higher income, being employed, having health insurance or a usual source of care, being from the Midwest compared with the South, being born in the U.S., reporting a recent mammogram, and reporting a recent gynecology visit (Tables $\mathbf{1 a}$ and $\mathbf{1 b}$ ). Among women receiving care at doctors' offices and HMOs, excellent or very good health status was associated with reporting a recent CBE.

In multivariate analysis (Table 2 ), women who received routine care in a location other than a clinic or health center, doctor's office or HMO, or hospital OPD were less likely than women receiving care from a doctor's office or HMO to have received a $\mathrm{CBE}$ within the past two years (adjusted OR $=0.4,95 \% \mathrm{CI}=0.3,0.7)$. Factors that were associated with recent $\mathrm{CBE}$ included location for receipt of routine health care, age, Hispanic ethnicity, education, region of the U.S., length of residence in the U.S., recent mammogram, and gynecology visit in the past year. Older women, Hispanic women, women with less than a high school education, no recent mammogram, no recent gynecology visit, or who were immigrants but lived in the U.S. 10 years or more were less likely than their respective reference groups to report a recent $\mathrm{CBE}$. 
Table 2. Adjusted odds ratios and percentage of women in the United States, aged 40 years or older, who had received a clinical breast examination in the past 2 years, National Health Interview Survey, $2005^{1}$

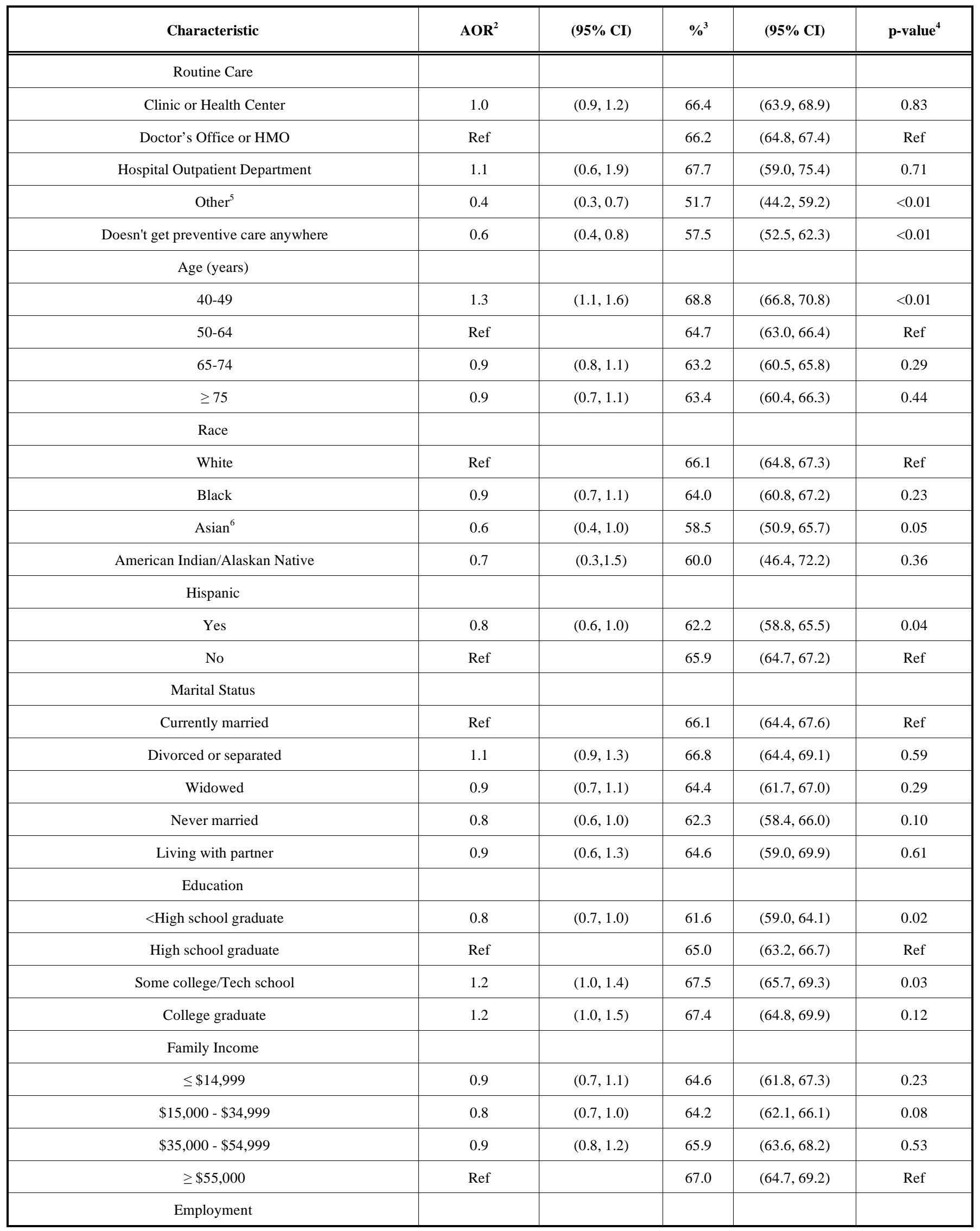




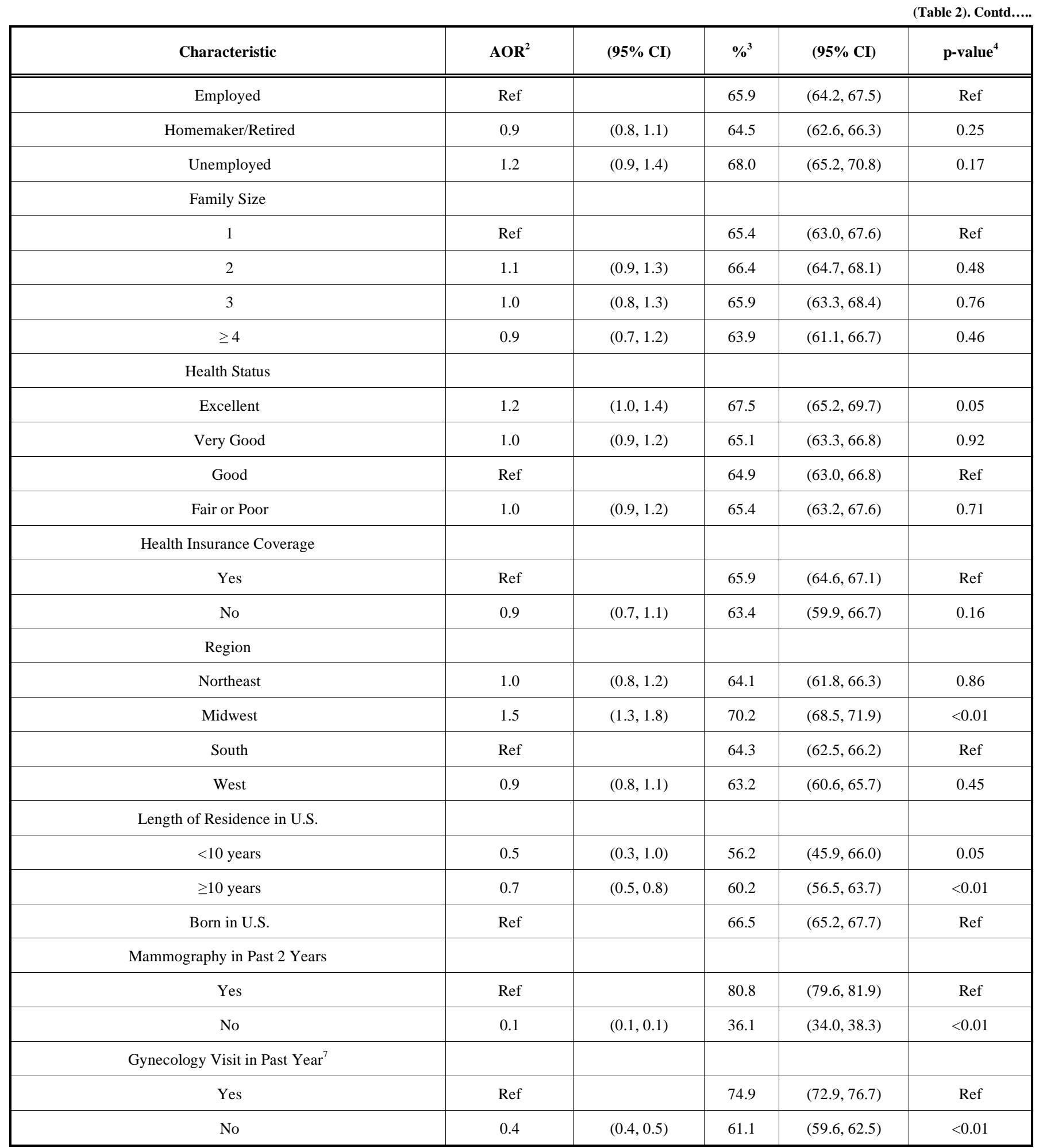

${ }^{1}$ Results are adjusted for all characteristics in the table. Estimates are weighted. Not ascertained, refused, or don't know responses were excluded.

${ }^{2}$ Adjusted odds ratio.

${ }^{3}$ Adjusted percentages (predicted marginals)

${ }^{4} \mathrm{~T}$-tests comparing characteristic levels to referent level.

${ }^{5}$ Hospital emergency room, some other place, or doesn't go to one place for routine care most often.

${ }^{6}$ Asian includes Asian Indian, Chinese, Filipino, and Other Asian.

${ }^{7}$ Respondents were asked if they had seen or talked to a doctor who specializes in women's health in the past 12 months.

\section{DISCUSSION}

The important differences in CBE rates observed in the current study by location of routine care may reflect differences in patient populations, differences in providers who practice in these settings, or variations in the healthcare environment. Minority women including those who are black or Hispanic are more likely than non-Hispanic white women to seek care from outpatient departments [8,9]. Many primary 
care visits occur in physicians offices and in HMOs, including for population subgroups such as racial minorities and Hispanic women. However, community health centers and hospital OPDs are also important providers of primary health care for many women including those who are recent immigrants to the United States [9,10]. Prior studies have shown that the women seen at community health centers are more likely to be up to date for breast cancer screening tests than low-income women in the general population [8]. The rates of recent CBE observed in this study were only slightly lower among women who reported they received routine health care at a clinic or health center, or hospital OPD, as compared with those who received health care at a doctor's office or HMO, and differences did not persist after adjustment for other factors. This suggests that after controlling for patient factors, these settings performed as well as doctors' offices or HMOs in delivering CBE to women. However, CBE rates were particularly low among women who received routine health care at other locations or who reported that they do not get preventive care anywhere.

The results of this study are consistent with those of previous studies that have shown that socioeconomic and demographic factors such as lower education, older age, and Hispanic ethnicity are associated with not having had a recent CBE [4]. Women who were unemployed and those with a larger family size were also less likely to have received a $\mathrm{CBE}$, although these findings did not persist in multivariate analysis. The relatively low CBE rates among Asian women, and among AI/AN women, may be due to a lack of access to culturally appropriate and sensitive preventive health care or to a lack of awareness of the importance of routine breast cancer screening. There may also be a need for preventive health services available for persons with lower health literacy. Studies have shown that persons with lower health literacy are less likely to undergo routine cancer screening $[11,12]$. Among women who received routine care at a doctors' office or HMO, those with a shorter duration of residence in the U.S were much less likely to have received a recent $\mathrm{CBE}$, with less than $30 \%$ of these women reporting a recent exam compared with $70 \%$ of women born in the U.S. In comparison, in clinics and health centers, $56 \%$ of women with a shorter duration of residence in the U.S. reported screening, which was not significantly different from women born in the U.S (66\%). Differences in patient acculturation or the availability of culturally appropriate health care services may partly account for these differential findings by health care setting.

The lower CBE rates among elderly women are consistent with results from prior studies that have shown lower CBE and mammography rates among older women [4]. Medical and scientific controversies exist about the value of routine breast cancer screening among women in the oldest age categories [13]. Uncertainty exists about whether the potential benefits of screening mammography outweigh the harms for elderly women. Nevertheless, about $58.3 \%$ of deaths from breast cancer among women occur among those aged 65 years or older. Our regression analysis suggests that the lower CBE use among older women is attributable to other patient, access and healthcare utilization factors.

Women who reported not receiving preventive care were somewhat less likely to have received a recent CBE along with those with no gynecology visit in the past year and those without a usual source of health care. Prior studies have shown that having a regular provider, continuity of care, and having a recent physician visit are related to breast cancer screening $[14,15]$. Women with more frequent contact with health care providers are more likely to have a CBE or a provider recommendation for other cancer screening tests. Continuity of care improves patient compliance with physician recommendations for cancer screening [14]. Information about continuity of care or about the reason for a provider visit was not assessed in the current study. Patients may be especially likely to undergo cancer screening in conjunction with a health maintenance visit or a physical examination [16].

Approximately $1 / 3$ of uninsured women in our sample reported not receiving any preventive care or receiving preventive care from an ER or other location, compared with < $3 \%$ of insured women. In addition, health insurance status was an important determinant of recent $\mathrm{CBE}$ after adjustment for age (Table 1a and 1b) but not in multivariate analysis (Table 2). Thus, after adjustment for location of receipt of routine care, family income, employment status, and other covariates associated with health insurance coverage and access to health care, health insurance was no longer an important predictor of recent CBE.

This current study did not assess reasons why providers did not perform a CBE such as physician attitudes or beliefs or patient refusal. Prior studies have suggested that clinician or patient embarrassment, lack of confidence in performing the examination, lack of time during a health care visit, and reliance on mammography as a preferred method of screening may be barriers to performing CBE [4]. In the current study, women who had had a mammogram in the past year were more likely to have received a recent CBE. However, about $17.0 \%$ of women who reported that they had had a recent mammogram indicated they had not received a CBE. Some providers may rely solely on mammography for routine breast cancer screening. Information about institutional guidelines for breast screening or other detailed characteristics of the locations where women received care was unavailable from NHIS. A further issue is that the current study lacked information about provider characteristics such as age, gender, or ethnicity. However, having a visit to a gynecologist in the past year was positively associated with having received a CBE. In addition, the current study did not provide detailed information about why women did or did not have a recent CBE. Information about the acceptability of $\mathrm{CBE}$ to the respondents was not available.

With respect to other limitations, response bias is a possibility because not all women identified as sample adults responded to the survey. In addition, self-reported information about breast cancer screening services may also differ from information obtained from the records of health care providers. Validation studies have suggested that patients tend to over-report their use of cancer screening services and under-estimate the time since their last screening [17,18]. The 2005 NHIS was limited by the small number of Asian and AI/AN respondents.

Our findings that factors related to healthcare access and utilization predicted $\mathrm{CBE}$ use, coupled with the finding that the vast majority of women reporting a recent mammogram 
also reported recent $\mathrm{CBE}$, may suggest that variations in CBE use may more likely be related to access to care than to sole reliance on mammography for breast cancer screening. After adjusting for differences in patient factors, results were similar for women seen by providers in clinics/health centers and hospital OPDs as compared with those seen in doctors' offices or HMOs. However, women receiving care in other locations were less likely to report a recent exam. The results of this study may be helpful to healthcare providers and program planners who are working to improve the quality of preventive care. Providers and planners in the U.S. should be aware of the lower rates of CBE, particularly among women with decreased access to health care.

\section{CONFLICT}

The findings and conclusions in this report are those of the authors and do not necessarily reflect the views of the Centers for Disease Control and Prevention.

\section{REFERENCES}

[1] United States Preventive Services Taskforce. Screening for Breast Cancer. What's New from the USPSTF. AHRQ Publication No. APPIP 02-0016, February 2002. Agency for Healthcare Research and Quality, Rockville, MD. http: //www.ahrq.gov/clinic/3rduspstf/ breastcancer/brcanwh.htm

[2] Bobo JK, Lee NC, Thames SF. Findings from 752,081 clinical breast examinations reported to a national screening program from 1995 through 1998. JNCI 2000; 92: 971-6.

[3] Barton MB, Harris R, Fletcher SW. The screening clinical breast examination: should it be done? How? JAMA 1999; 282: 1270-80.

[4] Meissner HI, Breen N, Yabroff KR. Whatever happened to clinical breast examinations? Am J Prev Med 2003; 25: 259-63.

[5] Caplan LS, Coughlin SS. Work-site breast cancer screening programs. A review. J Occ Health Nurs 1998; 46: 443-52.

[6] Steel RGD, Torrie JH, Dickey DA. Principles and procedures of statistics: a biometric approach, $3^{\text {rd }}$ ed. New York: McGraw Hill, 1997.

[7] Korn EL, Graubard BI. Analysis of health surveys. New York: John Wiley \& Sons, Inc. 1999.
[8] Regan J, Lefkowitz B, Gaston MH. Cancer screening among community health center women: eliminating the gaps. J Ambul Care Manage 1999; 22: 45-52.

[9] Forrest CB, Whelan EM. Primary care safety-net delivery sites in the United States. A comparison of community health centers, hospital outpatient departments, and physicians offices. JAMA 2000: 284: 2077-83.

[10] O'Malley AS, Mandelblatt J. Delivery of preventive services for low-income persons over age 50: a comparison of community health clinics to private doctors offices. J Comm Health 2003; 28 : 185: 97.

[11] Davis TC, Dolan NC, Ferreira MR, et al. The role of inadequate health literacy skills in colorectal cancer screening. Cancer Investigation 2001; 19: 1193-2000.

[12] Lindau ST, Tomori C, Lyons T, et al. The association of health literacy with cervical cancer prevention knowledge and health behaviors in a multiethnic cohort of women. Am J Obstet Gynecol 2002; 186: 938-43.

[13] Coughlin SS, Berkowitz Z, Hawkins NA, Tangka F. Breast and colorectal cancer screening and sources of cancer information among older women in the United States: results from the 2003 Health Information National Trends Survey. Prev Chronic Dis 2007; 4(3): A57.

[14] Haggerty J, Tamblyn R, Abrahamowicz M, et al. Screening mammography referral rates for women ages 50 to 69 years by recently licensed family physicians: physician and practice environment correlates. Prev Med 1999; 29: 391-404.

[15] Zapka JG, Stoddard A, Maul L, Costanza ME. Interval adherence to mammography screening guidelines. Med Care 1991; 29: 697707.

[16] Ruffin MT, Gorenflo DW, Woodman B. Predictors of screening for breast, cervical, colorectal, and prostatic cancer among communitybased primary care practices. J Am Board Fam Practice 2000; 13: $1-10$.

[17] Gordon NP, Hiatt RA, Lampert I. Concordance of self-reported data and medical record audit for six cancer screening procedures. JNCI 1993; 85: 566-70.

[18] McPhee SJ, Nguyen TT, Shema SJ, et al. Validation of recall of breast and cervical cancer screening by women in an ethnically diverse population. Prev Med 2002; 35: 463-73.

(C) Coughlin et al.; Licensee Bentham Open.

This is an open access article distributed under the terms of the Creative Commons Attribution License (http://creativecommons.org/licenses/by/2.5/), which permits unrestrictive use, distribution, and reproduction in any medium, provided the original work is properly cited. 
Appendix A. Characteristics of women in the United States, aged 40 years or older, by age, race, Hispanic ethnicity, and other characteristics according to their usual place of routine health care services, National Health Interview Survey, 2005 . $^{1}$

\begin{tabular}{|c|c|c|c|c|c|c|c|c|c|c|c|c|c|c|c|c|}
\hline \multirow[b]{2}{*}{ Characteristic } & \multirow[b]{2}{*}{ Total } & \multicolumn{3}{|c|}{$\begin{array}{l}\text { Clinic or Health Center } \\
\qquad(\mathbf{n}=1583)\end{array}$} & \multicolumn{3}{|c|}{$\begin{array}{l}\text { Doctor's Office or HMO } \\
\qquad(\mathrm{n}=\mathbf{8 5 4 8})\end{array}$} & \multicolumn{3}{|c|}{$\begin{array}{l}\text { Hospital Outpatient } \\
\text { Department }(n=145)\end{array}$} & \multicolumn{3}{|c|}{$\begin{array}{l}\text { Other }^{2} \\
(n=181)\end{array}$} & \multicolumn{3}{|c|}{$\begin{array}{c}\text { Doesn't get preventive } \\
\text { care } \\
\text { anywhere }(\mathbf{n}=\mathbf{5 8 0})\end{array}$} \\
\hline & & $\%$ & $(95 \% \mathrm{CI})$ & $\begin{array}{c}\text { p- } \\
\text { value }\end{array}$ & $\%$ & $(95 \% \mathrm{CI})$ & $\begin{array}{c}\text { p- } \\
\text { value }\end{array}$ & $\%$ & $\begin{array}{c}(95 \% \\
\text { CI })\end{array}$ & $\begin{array}{c}\text { p- } \\
\text { value }\end{array}$ & $\%$ & $(95 \% \mathrm{CI})$ & $\begin{array}{c}\text { p- } \\
\text { value }\end{array}$ & $\%$ & $(95 \% \mathrm{CI})$ & $\begin{array}{c}\text { p- } \\
\text { value }\end{array}$ \\
\hline Total & 11037 & 13.6 & $(12.7-14.4)$ & -- & 79.4 & (78.3-80.3) & -- & 1.0 & $(0.8-1.3)$ & -- & 1.6 & $(1.3-1.8)$ & -- & 4.5 & $(4.1-4.9)$ & -- \\
\hline \multicolumn{17}{|l|}{ Age (years) } \\
\hline $40-49$ & 3330 & 15.6 & $(14.1-17.3)$ & 0.18 & 74.9 & (73.1-76.6) & 0.02 & 0.9 & $(0.6-1.3)$ & 0.14 & 2.3 & $(1.8-2.9)$ & 0.06 & 6.3 & $(5.5-7.2)$ & 0.04 \\
\hline $50-64$ & 4044 & 14.4 & $(13.2-15.7)$ & ref & 77.7 & (76.0-79.3) & ref & 1.3 & $(0.9-1.7)$ & ref & 1.6 & $(1.2-2.1)$ & ref & 5.0 & $(4.3-5.9)$ & ref \\
\hline $65-74$ & 1738 & 10.7 & $(9.1-12.5)$ & $<0.01$ & 85.7 & (83.7-87.6) & $<0.01$ & $0.9^{\S}$ & $(0.4-2.1)$ & 0.43 & 0.9 & $(0.5-1.5)$ & 0.02 & 1.7 & $(1.2-2.5)$ & $<0.01$ \\
\hline$\geq 75$ & 1925 & 9.6 & $(8.2-11.1)$ & $<0.01$ & 87.4 & $(85.6-89.1)$ & $<0.01$ & 0.9 & $(0.5-1.4)$ & 0.15 & $0.6^{\S}$ & $(0.3-1.1)$ & $<0.01$ & 1.6 & $(1.1-2.2)$ & $<0.01$ \\
\hline \multicolumn{17}{|l|}{ Race } \\
\hline White & 9068 & 12.9 & (12.1-13.8) & ref & 80.3 & (79.2-81.4) & ref & 0.8 & $(0.6-1.1)$ & ref & 1.3 & $(1.1-1.6)$ & ref & 4.6 & $(4.1-5.1)$ & ref \\
\hline Black & 1576 & 15.2 & $(13.2-17.4)$ & 0.04 & 75.7 & $(73.0-78.2)$ & $<0.01$ & 2.5 & $(1.7-3.7)$ & $<0.01$ & 2.7 & $(1.8-3.9)$ & 0.01 & 3.9 & $(2.8-5.4)$ & 0.32 \\
\hline $\operatorname{Asian}^{3}$ & 287 & 17.5 & (12.6-23.8) & 0.11 & 73.2 & $(66.4-79.0)$ & 0.03 & $2.6^{\S}$ & $(1.3-5.1)$ & 0.04 & $2.1^{\S}$ & $(0.9-4.7)$ & 0.39 & 4.6 & $(2.7-7.7)$ & 0.98 \\
\hline $\begin{array}{l}\text { American Indian/ } \\
\text { Alaskan Native }\end{array}$ & 78 & 35.9 & $(23.8-50.1)$ & $<0.01$ & 59.7 & $(45.3-72.5)$ & $<0.01$ & $* *$ & & & $* *$ & & & $* *$ & & \\
\hline \multicolumn{17}{|l|}{ Hispanic } \\
\hline Yes & 1393 & 22.2 & $(19.7-25.0)$ & $<0.01$ & 59.5 & $(56.1-62.9)$ & $<0.01$ & 3.9 & $(2.5-6.1)$ & $<0.01$ & 3.0 & $(2.0-4.4)$ & $<0.01$ & 11.3 & $(9.5-13.5)$ & $<0.01$ \\
\hline No & 9644 & 12.6 & $(11.8-13.5)$ & ref & 81.4 & $(80.4-82.4)$ & ref & 0.8 & $(0.6-1.0)$ & ref & 1.4 & $(1.2-1.7)$ & ref & 3.8 & $(3.4-4.2)$ & ref \\
\hline \multicolumn{17}{|l|}{ Marital Status } \\
\hline Currently married & 4896 & 12.5 & $(11.5-13.6)$ & ref & 82.0 & $(80.7-83.2)$ & ref & 0.8 & $(0.6-1.2)$ & ref & 1.3 & $(1.1-1.7)$ & ref & 3.4 & $(2.9-3.9)$ & ref \\
\hline Divorced or separated & 2393 & 15.3 & $(13.6-17.2)$ & $<0.01$ & 75.1 & $(73.0-77.2)$ & $<0.01$ & 1.4 & $(0.9-2.2)$ & 0.06 & 1.9 & $(1.3-2.6)$ & 0.14 & 6.3 & $(5.3-7.6)$ & $<0.01$ \\
\hline Widowed & 2447 & 13.6 & (11.0-16.8) & 0.47 & 75.3 & $(70.4-79.7)$ & $<0.01$ & $1.1^{\S}$ & $(0.6-2.1)$ & 0.47 & $2.1^{\S}$ & $(1.1-3.9)$ & 0.29 & 7.9 & $(4.9-12.6)$ & 0.02 \\
\hline Never married & 966 & 18.1 & (14.9-21.7) & $<0.01$ & 70.7 & $(66.9-74.2)$ & $<0.01$ & 2.0 & $(1.3-3.0)$ & 0.01 & 1.9 & $(1.1-3.1)$ & 0.30 & 7.4 & $(5.9-9.3)$ & $<0.01$ \\
\hline Living with partner & 269 & 16.2 & $(12.2-21.3)$ & 0.11 & 74.4 & $(69.2-79.1)$ & $<0.01$ & $* *$ & & & $2.6^{\S}$ & $(1.2-5.7)$ & 0.25 & 5.8 & $(3.7-9.1)$ & 0.07 \\
\hline \multicolumn{17}{|l|}{ Education } \\
\hline $\begin{array}{l}<\text { High school gradu- } \\
\text { ate }\end{array}$ & 2146 & 20.8 & $(18.6-23.2)$ & $<0.01$ & 64.2 & $(61.6-66.7)$ & $<0.01$ & 2.6 & $(1.8-3.8)$ & $<0.01$ & 3.5 & $(2.5-4.9)$ & $<0.01$ & 8.9 & $(7.4-10.5)$ & $<0.01$ \\
\hline $\begin{array}{l}\text { High school graduate/ } \\
\text { GED }\end{array}$ & 3377 & 14.4 & $(13.0-15.9)$ & ref & 78.5 & $(76.8-80.1)$ & ref & 0.9 & $(0.6-1.3)$ & ref & 1.3 & $(0.9-1.8)$ & ref & 4.9 & $(4.2-5.7)$ & ref \\
\hline $\begin{array}{l}\text { Some college/ } \\
\text { Tech school }\end{array}$ & 2922 & 12.9 & (11.6-14.3) & 0.11 & 81.4 & $(79.8-83.0)$ & $<0.01$ & 0.7 & $(0.5-1.0)$ & 0.34 & 1.2 & $(0.8-1.7)$ & 0.71 & 3.8 & $(3.1-4.7)$ & 0.04 \\
\hline College graduate & 2460 & 9.9 & $(8.4-11.6)$ & $<0.01$ & 85.8 & (83.9-87.5) & $<0.01$ & 0.6 & $(0.3-0.9)$ & 0.10 & 1.2 & $(0.8-1.8)$ & 0.88 & 2.5 & $(2.0-3.2)$ & $<0.01$ \\
\hline \multicolumn{17}{|l|}{ Family Income } \\
\hline$\leq \$ 14,999$ & 2360 & 21.5 & $(19.1-24.2)$ & $<0.01$ & 60.3 & $(57.5-63.1)$ & $<0.01$ & 2.7 & $(1.8-3.9)$ & $<0.01$ & 3.9 & $(2.7-5.5)$ & $<0.01$ & 11.6 & $(9.8-13.7)$ & $<0.01$ \\
\hline$\$ 15,000-\$ 34,999$ & 3293 & 17.5 & $(15.7-19.3)$ & $<0.01$ & 72.5 & $(70.3-74.6)$ & $<0.01$ & 1.3 & $(0.8-2.0)$ & 0.01 & 2.1 & $(1.4-3.1)$ & 0.04 & 6.7 & $(5.6-8.0)$ & $<0.01$ \\
\hline$\$ 35,000-\$ 54,999$ & 1980 & 13.0 & $(11.3-14.8)$ & $<0.01$ & 80.6 & $(78.4-82.6)$ & $<0.01$ & 1.1 & $(0.7-1.9)$ & 0.04 & 1.2 & $(0.7-2.0)$ & 0.68 & 4.1 & $(3.2-5.3)$ & $<0.01$ \\
\hline$\geq \$ 55,000$ & 3404 & 9.8 & $(8.6-11.1)$ & ref & 86.7 & $(85.3-88.0)$ & ref & $0.4^{\S}$ & $(0.2-0.7)$ & ref & 1.1 & $(0.7-1.5)$ & ref & 2.0 & $(1.5-2.7)$ & ref \\
\hline \multicolumn{17}{|l|}{ Employment } \\
\hline Employed & 5312 & 14.0 & $(12.4-15.8)$ & ref & 80.5 & $(78.6-82.2)$ & ref & 0.7 & $(0.5-1.0)$ & ref & 1.2 & $(1.0-1.5)$ & ref & 3.6 & $(3.1-4.1)$ & ref \\
\hline Homemaker/Retired & 4264 & 13.9 & $(12.3-15.6)$ & 0.88 & 77.1 & $(75.0-79.1)$ & $<0.01$ & 0.8 & $(0.5-1.2)$ & 0.77 & 2.2 & $(1.4-3.2)$ & 0.04 & 6.1 & $(4.9-7.5)$ & $<0.01$ \\
\hline Unemployed & 1440 & 16.1 & $(14.0-18.5)$ & 0.13 & 72.5 & $(69.8-75.1)$ & $<0.01$ & 2.6 & $(1.8-3.9)$ & $<0.01$ & 2.3 & $(1.6-3.4)$ & 0.02 & 6.4 & $(5.1-8.1)$ & $<0.01$ \\
\hline
\end{tabular}




\begin{tabular}{|c|c|c|c|c|c|c|c|c|c|c|c|c|c|c|c|c|}
\hline \multicolumn{17}{|l|}{ Family Size } \\
\hline 1 & 4201 & 13.4 & $(12.0-15.0)$ & ref & 76.4 & $(74.6-78.1)$ & ref & 1.6 & $(1.2-2.2)$ & ref & 1.8 & $(1.4-2.4)$ & ref & 6.7 & $(5.6-7.9)$ & ref \\
\hline 2 & 3966 & 13.3 & $(12.0-14.6)$ & 0.86 & 80.8 & $(79.2-82.2)$ & $<0.01$ & 0.9 & $(0.7-1.3)$ & $<0.01$ & 1.5 & $(1.2-2.0)$ & 0.37 & 3.5 & $(2.9-4.2)$ & $<0.01$ \\
\hline 3 & 1375 & 11.8 & $(10.1-13.8)$ & 0.20 & 80.7 & $(78.3-82.9)$ & $<0.01$ & $1.2^{\S}$ & $(0.5-3.0)$ & 0.44 & 1.2 & $(0.7-1.9)$ & 0.09 & 5.1 & $(4.1-6.4)$ & 0.07 \\
\hline$\geq 4$ & 1495 & 16.3 & $(13.6-19.3)$ & 0.08 & 75.3 & $(72.0-78.3)$ & 0.52 & $0.9^{\S}$ & $(0.5-1.7)$ & 0.07 & 1.7 & $(1.1-2.7)$ & 0.83 & 5.8 & $(4.5-7.5)$ & 0.36 \\
\hline \multicolumn{17}{|l|}{ Health Status } \\
\hline Excellent & 2224 & 11.3 & $(9.7-13.0)$ & $<0.01$ & 82.5 & $(80.5-84.3)$ & $<0.01$ & 0.7 & $(0.5-1.2)$ & 0.19 & 1.7 & $(1.2-2.5)$ & 0.95 & 3.8 & $(3.1-4.7)$ & $<0.01$ \\
\hline Very Good & 3270 & 12.6 & $(11.3-14.0)$ & 0.03 & 81.7 & $(80.1-83.2)$ & $<0.01$ & 0.7 & $(0.5-1.2)$ & 0.25 & 1.1 & $(0.7-1.7)$ & 0.04 & 3.9 & $(3.2-4.6)$ & $<0.01$ \\
\hline Good & 3316 & 14.7 & $(13.3-16.3)$ & ref & 76.6 & $(74.8-78.2)$ & ref & 1.1 & $(0.7-1.6)$ & ref & 1.7 & $(1.3-2.2)$ & ref & 5.9 & $(5.1-7.0)$ & ref \\
\hline Fair or Poor & 2222 & 18.0 & $(16.0-20.2)$ & $<0.01$ & 73.1 & (70.7-75.4) & 0.01 & 1.8 & $(1.3-2.5)$ & 0.03 & 2.1 & $(1.5-3.1)$ & 0.33 & 4.9 & $(3.9-6.2)$ & 0.14 \\
\hline \multicolumn{17}{|c|}{$\begin{array}{c}\text { Have Usual Source of } \\
\text { Care }\end{array}$} \\
\hline Yes & 10203 & 13.9 & $(13.0-14.8)$ & ref & 83.5 & $(82.6-84.5)$ & ref & 1.0 & $(0.8-1.3)$ & ref & 0.5 & $(0.4-0.7)$ & ref & 1.0 & $(0.8-1.3)$ & ref \\
\hline No & 833 & 9.8 & $(7.4-12.8)$ & $<0.01$ & 25.9 & $(22.2-30.0)$ & $<0.01$ & $1.0^{\S}$ & $(0.5-2.0)$ & 0.86 & 14.9 & $\begin{array}{c}(12.1- \\
18.3)\end{array}$ & $<0.01$ & 48.4 & $\begin{array}{c}(44.2- \\
52.5)\end{array}$ & $<0.01$ \\
\hline \multicolumn{17}{|c|}{$\begin{array}{c}\text { Health Insurance } \\
\text { Coverage }\end{array}$} \\
\hline Yes & 9838 & 12.4 & (11.6-13.3) & ref & 83.8 & $(82.8-84.7)$ & ref & 0.9 & $(0.7-1.2)$ & ref & 0.8 & $(0.7-1.0)$ & ref & 2.1 & $(1.8-2.5)$ & ref \\
\hline No & 1166 & 20.5 & $(15.8-26.1)$ & $<0.01$ & 43.5 & $(35.0-52.3)$ & $<0.01$ & $* *$ & & & 6.9 & $(5.0-9.5)$ & $<0.01$ & 25.5 & $\begin{array}{c}(19.3- \\
32.8)\end{array}$ & $<0.01$ \\
\hline \multicolumn{17}{|l|}{ Region } \\
\hline Northeast & 2049 & 9.2 & (7.9-10.7) & 0.53 & 85.5 & (83.3-87.5) & 0.02 & $1.2^{\S}$ & $(0.6-2.2)$ & 0.32 & 1.6 & $(1.1-2.6)$ & 0.79 & 2.4 & $(1.7-3.4)$ & $<0.01$ \\
\hline Midwest & 2609 & 22.0 & (19.8-24.4) & $<0.01$ & 72.8 & $(70.3-75.2)$ & $<0.01$ & 0.9 & $(0.7-1.3)$ & 0.49 & 0.8 & $(0.5-1.3)$ & 0.01 & 3.4 & $(2.7-4.2)$ & $<0.01$ \\
\hline South & 4080 & 9.8 & $(8.7-11.0)$ & ref & 82.3 & (80.7-83.8) & ref & 0.8 & $(0.5-1.2)$ & ref & 1.5 & $(1.2-2.0)$ & ref & 5.6 & $(4.8-6.5)$ & ref \\
\hline West & 2299 & 14.3 & $(12.5-16.2)$ & $<0.01$ & 76.0 & $(74.0-78.0)$ & $<0.01$ & 1.5 & $(1.1-2.2)$ & 0.03 & 2.4 & $(1.8-3.1)$ & 0.03 & 5.7 & $(4.9-6.8)$ & 0.85 \\
\hline \multicolumn{17}{|c|}{$\begin{array}{c}\text { Length of Residence in } \\
\text { U.S. }\end{array}$} \\
\hline$<10$ years & 180 & 26.6 & (18.9-36.2) & $<0.01$ & 47.0 & $(38.5-55.6)$ & $<0.01$ & $3.7^{\S}$ & $(1.6-8.4)$ & 0.06 & $3.7^{\S}$ & $(1.9-7.1)$ & 0.06 & 19.0 & $\begin{array}{l}(13.0- \\
26.9)\end{array}$ & $<0.01$ \\
\hline$\geq 10$ years & 1405 & 17.8 & $(15.8-20.1)$ & $<0.01$ & 69.4 & $(66.2-72.3)$ & $<0.01$ & 3.1 & $(2.1-4.8)$ & $<0.01$ & 2.8 & $(1.8-4.2)$ & 0.02 & 6.9 & $(5.5-8.6)$ & $<0.01$ \\
\hline Born in U.S. & 9417 & 12.7 & $(11.8-13.6)$ & ref & 81.4 & $(80.3-82.4)$ & ref & 0.7 & $(0.6-0.9)$ & ref & 1.3 & $(1.1-1.6)$ & ref & 3.9 & $(3.4-4.4)$ & ref \\
\hline \multicolumn{17}{|c|}{$\begin{array}{l}\text { Mammography in Past } \\
2 \text { Years }\end{array}$} \\
\hline Yes & 6537 & 13.2 & $(12.1-14.3)$ & ref & 83.8 & $(82.6-85.0)$ & ref & 0.9 & $(0.7-1.3)$ & ref & 0.8 & $(0.6-1.0)$ & ref & 1.3 & $(1.1-1.6)$ & ref \\
\hline No & 3538 & 15.2 & $(13.7-16.9)$ & 0.04 & 69.2 & $(67.2-71.2)$ & $<0.01$ & 1.1 & $(0.8-1.5)$ & 0.53 & 3.4 & $(2.7-4.2)$ & $<0.01$ & 11.1 & $(9.9-12.5)$ & $<0.01$ \\
\hline \multicolumn{17}{|c|}{$\begin{array}{c}\text { Gynecology Visit in } \\
\text { Past Year }\end{array}$} \\
\hline Yes & 3757 & 10.5 & $(9.3-11.7)$ & $<0.01$ & 86.0 & (84.5-87.3) & $<0.01$ & 1.5 & $(1.0-2.1)$ & 0.03 & 0.9 & $(0.6-1.3)$ & $<0.01$ & 1.2 & $(0.9-1.7)$ & $<0.01$ \\
\hline No & 7210 & 15.6 & $(14.5-16.8)$ & ref & 74.4 & $(73.0-75.8)$ & ref & 0.8 & $(0.6-1.2)$ & ref & 2.1 & $(1.7-2.6)$ & ref & 7.0 & $(6.3-7.8)$ & ref \\
\hline
\end{tabular}

${ }^{1}$ Except for age, results are adjusted for age using survey population. Estimates are weighted; p-values are for tests comparing characteristic levels to referent level. Not ascertained, refused, or don't know responses were excluded.

${ }^{2}$ Hospital emergency room, some other place, or doesn't go to one place for routine care most often.

${ }^{3}$ Asian includes Asian Indian, Chinese, Filipino, and Other Asian.

${ }^{4}$ Respondents were asked if they had seen or talked to a doctor who specializes in women's health in the past 12 months.

${ }^{\S}$ Relative standard error $30-50 \%$, interpret results with caution.

**Not reportable, sample size $<30$ and/or relative standard error $>50 \%$. 